Forthcoming in Erkenntnis. Please cite the published version. https://doi.org/10.1007/s10670$\underline{021-00475-\mathrm{W}}$

\title{
A Dilemma for Reductive Compatibilism ${ }^{1}$
}

\begin{abstract}
:
A common compatibilist view says that we are free and morally responsible in virtue of the ability to respond aptly to reasons. Many hold a version of this view despite disagreement about whether free will requires the ability to do otherwise. The canonical version of these views is reductive. It reduces the pertinent ability to a set of modal properties that are more obviously compatible with determinism, like dispositions. I argue that this and any reductive view of abilities faces a significant challenge: it cannot adequately explain the freedomgrounding element of this ability. The problem has the form of a dilemma. This leaves reasonsresponsive compatibilists with two options: abandon theories of free will grounded in abilities or abandon reductive theories of abilities.
\end{abstract}

\section{Introduction}

There is a popular inspirational quote shared on the internet that articulates a powerful and intuitive thought about the nature of free agents: "between stimulus and response there is space. In that space is our power to choose our response. In our response lies our growth and our freedom". ${ }^{2}$ It is this actionable "space" between what happens to us and what we do that makes us morally responsible beings.

This spatial metaphor is, of course, just a metaphor. But it gestures at an important conceptual point about the nature of free agency. Free agents have an ability to choose (or decide) what to do. In virtue of this ability, free agents settle for themselves what they are going to do. Put otherwise, free agents make a difference to what happens by exercising their ability to choose. This difference-making is unlike the happenings that result from the activity of non-agents in the world, for whom what happens next is, in comparison, just a reaction to what came before.

I will argue that this basic conceptual point about the kind of ability that characterizes free agents is the source of a serious problem for compatibilists, one to which we have been insufficiently attentive. I will proceed with a widespread view in mind as an example. The view

\footnotetext{
1 (Acknowledgments)

2 The quote is often misattributed to Viktor Frankl. See: https://quoteinvestigator.com/2018/02/18/response/.
} 
holds that we are free and morally responsible in virtue of the ability to respond aptly to reasons. Call the view reasons-responsive compatibilism. Many hold a version of this view, in spite of disagreements about whether or not free will requires the ability to do otherwise. ${ }^{3}$

The canonical version of such views is reductive. Abilities are reduced to modal properties that are more obviously compatible with determinism, like dispositions (e.g. Fischer and Ravizza (1998)). I argue that this reductive view faces a significant challenge: it cannot adequately explain the freedom-grounding element of abilities.

The literature seems to have a sense of this problem for the reductive view insofar as there are specific criticisms of specific versions of it. For instance, (Watson 2004: 67) worries that actual sequence views in the style of Fischer and Ravizza (1994) try to understand abilities in terms of “counterincentive". And Clarke (2009, 2015) and Whittle (2010) have each argued that the "new dispositionalists" who favor a reductive account of the ability-to-do-otherwise in terms of dispositions, like Fara (2008) and Vihvelin (2013), fail for both extensional and conceptual reasons. Yet no one has articulated the general problem for reductive compatibilism by abstracting away from the actual sequence versus alternative possibilities debate. The problem is that by reducing the pertinent abilities to dispositions, we lose out on an important conceptual constraint in offering a theory of free will: that we explain how free agents make a difference to what happens by exercising their ability to choose (or try, or decide) what to do.

I raise the general problem in the form of a dilemma. This problem seems to extend to any reductive compatibilist view, regardless of the proposed reductive base. In fact, the problem is a general metaphysical problem with reductionism about free will in terms of abilities,

\footnotetext{
3 Wolf (1990), Fischer and Ravizza (1998), Nelkin (2011), McKenna (2013), Vargas (2013), and Vihvelin (2013), among others, each defend some version of this view despite disagreement about whether free will requires the ability to do otherwise. Sartorio (2016) is a kind of reasons-responsive theorist, but her view does not turn on abilities. "Reasonsresponsive compatibilism" usually picks out views in the style of Fischer and Ravizza (1998). I use the term more broadly. I would include Susan Wolf (1990) and Dana Nelkin (2011) in this camp, who defend what is sometimes called the "Reason view". Kadri Vihvelin's (2013) view is often labeled a form of "dispositional compatibilism", since her view involves the disposition to choose on the basis of reasons. All of these views understand free will is to be had in the ability to respond aptly to reasons, in spite of disagreement about, for instance, whether moral responsibility requires the ability to do otherwise.
} 
irrespective of the truth of determinism. Yet whereas libertarians have not explicitly endorsed the kind of reductionism at issue, this problem badly impacts extent compatibilist views, because the reduction is an important part of the standard case for compatibilism. ${ }^{4}$ My focus, then, will be on compatibilist views.

The dilemma leaves reasons-responsive compatibilists, and compatibilists in general, with two options: abandon theories grounded in abilities (e.g., Sartorio 2016) or abandon reductive theories of abilities (e.g., Wolf 1990, Nelkin 2011, McKenna 2019).

\section{Abilities, Dispositions, and the Gap Problem}

A traditional way of construing the problem of free will and determinism begins with the necessary and sufficient conditions for moral responsibility. One of these necessary conditions is having a certain kind and degree of control over one's actions. ${ }^{5}$ Call the kind and degree of control sufficient for meeting this condition on moral responsibility free will. A common assumption among the majority of disputants in the free will debate is that the control condition is to be understood in terms of abilities. So, to say that there is some free will ability is to say that there is an ability, or collection of abilities, such that when had by an agent, that agent meets the control condition of moral responsibility. Then arguments are marshalled as to whether some candidate free will ability is compatible with determinism, the thesis that the past and the laws of nature entail one unique future. ${ }^{6}$

\footnotetext{
${ }^{4}$ It is possible that some event-causal libertarian views of free will have implicit commitments to the kind of reductionism at issue in this paper. (Agent-causal libertarians do not endorse reductionism, so they can be set aside). But there are tricky interpretive issues here. I will discuss these complications at length in footnotes 27 and 29 . My view is that a further discussion is needed about how event-causal libertarians treat the ontological status of abilities, one that falls outside the scope of this paper. The general problem for reductionism about abilities is most clearly articulable, and most important for the ongoing debate about free will, in the context of contemporary accounts of reasons-responsive compatibilism.

${ }^{5}$ It is generally accepted that there is at least one other condition on moral responsibility besides a metaphysical or control condition: a knowledge condition. It is an open question whether not the conditions for moral responsibility are exhausted by these two conditions. I discuss the problem in terms of necessary and sufficient conditions for the sake of clarity in presenting the problems. Less strictly, what we are after is a theory or explanation of what moral responsibility requires. I should also note that although it is not uncontroversial to frame the problem in terms of moral responsibility, it is also not universally accepted. For some likeminded philosophers, see: Pereboom (2001: xxii), Mele (2006: 17), and McKenna (2008: 187).

${ }^{6}$ More formally, determinism is the thesis that two propositions, one describing the past at some given time, and another describing the laws of nature, together entail a proposition describing the one unique future.
} 
How might a compatibilist proceed? They need to offer (1) an intuitively candidate free will ability, which is (2) compatible with determinism. Consider a classic view. Philosophers like Ayer (1954), Schlick (1939), and Moore (1912) attempted to reduce abilities to sets of counterfactual conditionals, e.g., of the form: "If I had tried to do otherwise, then I would have done otherwise".

These counterfactuals were meant to reveal and reductively explain freedom-relevant capacities of the agent. Compare: in a deterministic world there is no obvious threat to the counterfactual claim that if I were to drop salt into water, it would dissolve. This counterfactual claim tells us something important about the nature of salt, namely, that it has the disposition to dissolve in water. Likewise, counterfactuals about what some agent would have done if they had tried to do differently reveals something important about our nature as agents: So, we move from abilities to determinism-friendly counterfactuals, identifying the free will ability as an ability to do otherwise. This is a clever tactic. But this sort of account fails by extensional inadequacy (e.g. Lehrer 1968). Imagine an agent who is so afraid of the color red that they would never try (or want or decide) to eat a piece of red candy. But say that this agent is otherwise psychologically normal. If so, it seems true that if they had tried to eat the red candy, then they would have. So, the classical analysis renders the false verdict that agents are able to do what they cannot do in light of psychological incapability (in this case, eat red candy).

How might one keep the cleverness of this strategy, without falling prey to its extensional failure? Instead of focusing on counterfactuals, we could focus on dispositions as a reductive base for abilities. What is a disposition? Let's consider an example. Fragility is the disposition of some object to break (and so manifest fragility) when put into certain kinds of situations, like being dropped. In other words, dispositions manifest under specifiable stimulus conditions (cf. Martin 1994, Lewis 1997, Manley and Wasserman 2007, inter alia). Dispositions are presumptively compatible with determinism. We can see why by thinking about the close relationship between dispositions and counterfactuals. In a deterministic world there is no obvious threat to the counterfactual claim 
that if I were to drop salt into water, it would dissolve. And this is true of salt which never comes into contact with water. So, salt's solubility is not threatened by determinism. If one were to offer a reductive analysis of the free will ability in terms of dispositions, one could secure the ability's compatibility with determinism.

This is the strategy that many reasons-responsive compatibilists take. For the sake of argument let's assume that the ability that gives us control sufficient for moral responsibility is the ability to respond aptly to reasons (where this ability involves being able to respond to a relatively high degree of such reasons). ${ }^{7}$ In other words, the free will ability is reasons-responsiveness. Here is an apparently promising way, it seems, to secure the compatibility of free will and determinism: reduce the reasons-responsive ability to the dispositions necessary and sufficient for having that ability. They are presumptively compatible with determinism. And if the ability is identified with these dispositions, then the agent's ability is not mysterious in the least. Her ability to respond aptly to reasons is just her being disposed to respond aptly to reasons. We can moreover learn about the nature of her rational dispositions by imaginatively checking what reasons she would take as sufficient in counterfactual situations. Fischer and Ravizza, for instance, appear to take up this strategy. ${ }^{8}$ First, they analyze reasons-responsiveness as dispositions to recognize and react to sufficient reasons and follow through by explaining these dispositions in terms of a collection of true counterfactuals (1998: ch. 3, sections IV.2 and IV.3). This provides an explanatorily fleshed out view of what the ability to respond to reasons is, how we can know about it, and why it is compatible with determinism.

A recent instance of this reductive strategy (disregarding areas of disagreement with Fischer and Ravizza) is found in Vihvelin (2013). She argues that our narrow abilities, abilities in the sense of those things we can do but could remain unexercised, "are structurally like the so-

\footnotetext{
${ }^{7}$ I'll omit this qualification in the discussion to follow.

${ }^{8}$ McKenna (2019: 23, ft. 15) claims that Fischer and Ravizza never commit to a reductive view. Nevertheless, I believe it is the most promising interpretation of their view, since, if it succeeds, it secures the compatibility claim. McKenna's alternative suggestion for them does not. I'll discuss this kind of alternative in section 6 . Thanks to an anonymous reviewer for raising this issue.
} 
called intrinsic dispositions of medium-sized objects-dispositions like fragility, elasticity, solubility, and so on" (2013: 169). How so? They are both three-place relations: fragile glass has a disposition to break when dropped, and I have the ability to speak French given the opportunity. She goes on to say that "our narrow abilities", what in us makes us able to do things without considering our opportunities, "are either intrinsic dispositions or bundles of intrinsic dispositions" (2014: 169). And she goes on to argue that the abilities relevant to free will are wide abilities to respond to reasons. Wide abilities involve not only narrow abilities but also opportunities to exercise them. Opportunities on this view are understood as situations amenable to the manifestation of our dispositions. And since dispositions are compatible with determinism, we have a compelling compatibilist account of abilities. ${ }^{9}$ This reductive approach may go some ways towards explaining, as Vargas (2013: 139, ft. 6) put it, the "uncontested consensus about the possibility of reasons sensitivity even under determinism."

Despite the cleverness of this strategy, some incompatibilists have been skeptical about the sense of ability to be gleaned from this kind of reductive project (e.g. Van Inwagen (1983), inter alia). The source of this skepticism stems from a simple point: dispositions do not seem to be the same thing as abilities. Here is Peter van Inwagen's archetypal way of making the distinction between dispositions (causal powers and capacities) and abilities (agentive powers):

For a man to have the capacity to understand French is for him to be such that if he were placed in certain circumstances, which wouldn't be hard to delimit, and if he were to hear French spoken, then, willy-nilly, he would understand what was being said. But if a man can speak. French, it certainly does not follow that there are any circumstances in which he would, willy-nilly, speak French. The concept of a causal power or capacity would seem to be the concept of an invariable disposition to react to certain determinate changes in the environment in certain determinate ways, whereas the concept of an agent's power to act would seem not to be the concept of a power that is dispositional or reactive, but rather, the concept of a power to originate changes in the environment. (1983:10-11)

\footnotetext{
9 To be clear, Vihvelin argues that free will and determinism are compatible prior to her endorsing this dispositional view of abilities by attacking incompatibilist arguments. That our abilities are explicable as bundles of dispositions is meant to explain why the ability to respond aptly to reasons is compatible with determinism. More forthcoming in section 6 .
} 
In other words, abilities involve something more than the mere reactivity displayed by dispositions. ${ }^{10}$ But what is this something more?

Well, the sense of "can" involved in the statement "the fragile vase can break when dropped" involves no power of the vase to instigate novel changes, unlike a typical "can" claim involving an agent's ability. Instead, the vase's fragility involves a reaction to the condition of it striking a hard surface. One could think of capacities, skills, and talents in a likewise manner. For instance, one cannot help understanding spoken French, if one is fluent in the language. I myself am disposed to become angry when someone insults me, disposed to laugh at a good joke, and disposed to sweat when I run. Dispositions like these, whether had by objects or persons, involve stimulus conditions and manifestations of inner natures. A stimulus condition is a set of circumstances that primes a reaction. And to manifest something is to perhaps express and make apparent some inward nature.

There are of course similarities between dispositions, but there are also important differences. A disposition can be interfered with (finked or masked) such that it will not manifest in its stimulus condition. ${ }^{11}$ For example, a fragile glass will not break when wrapped in bubble wrap. Abilities can be masked and finked too, a fact that some dispositional compatibilists have focused on (Fara 2008; Smith 1997, 2003). But this makes sense if we think that abilities and dispositions are both species of the same modal genus, like powers or potentials (Vetter 2013: 8). Yet the other ways we think about abilities do not overlap so nicely with dispositions. In contrast, one is able to perform some action if one is put together the right way so as to have the power to do said action and one has the opportunity to exercise that ability. An opportunity is a set of circumstances that makes an action possible. Opportunities are not mechanism triggers. They are seized upon or missed. One elects if and when to speak. When I speak French, I do more than

\footnotetext{
10 Two points. First, van Inwagen means "willy-nilly" in the sense of happening like it or not, rather than happening haphazardly. I'll use it in this sense too. Second, ordinary talk of abilities is quite permissive. We can say perfectly well of my car that it is able to handle rough terrain in virtue of its four-wheel drive and suspension. The abilities at issue in this discussion are the sort at issue in the free will debate, which are relevant to human agency.

${ }^{11}$ For examples, see Martin (1994) and Lewis (1997).
} 
manifest or express my inward knowledge of its grammar and vocabulary in certain circumstances. I do more than manifest the necessary features of myself relevant to speaking French. I have control over these elements. I direct them and govern their expression such that I have, in the relevant sense, the ability to speak the language. I myself settle the question of what I will say. Despite similarity, then, there seems to be an important intuitive difference between dispositions and abilities.

We need to be precise in developing this difference. Notice that Van Inwagen talks about "invariable dispositions" in his criticism of the compatibilist view. This is a mistake at best and is question-begging at worst. We will need to consider a more sophisticated metaphysics of dispositions.

Many dispositions are multi-track, best characterized by many pairs of stimulus and manifestation conditions. Many dispositions are had by their bearers to a greater or lesser degree (Manley and Wasserman 2007). The dispositions under discussion are all plausibly multi-track, gradable dispositions. Indeed, some dispositions have only one stimulus condition and many manifestations, and conversely, some dispositions have many stimulus conditions and a single manifestation. For example, there are lots of ways to break the fragile glass: dropping, throwing, clumsily handling, being hit with precisely 5 newtons of force, and so on. Likewise, there are lots of ways for that the fragile glass to break. It can crack this way or that way or even shatter completely. And perhaps the fragile glass is less fragile than the nice china, which seem to break when I simply look at it. Given this, I would disagree with van Inwagen that dispositions manifest willy-nilly because they are "invariable". They are willy-nilly insofar as it is not up to the bearer of the disposition that the disposition manifests.

Perhaps Van Inwagen thinks that all dispositions are what Prior, Pargetter, and Jackson (1982: 251) call "surefire" dispositions. Surefire dispositions are such that their intrinsic properties and relevant stimulus conditions, understood as the relevant set of antecedent circumstances, are a causally operative sufficient condition for the manifestations of the disposition. This is indeed 
question-begging, because not all dispositions are surefire. ${ }^{12}$ Consider the radioactive atom that has an indeterministic disposition to decay or not decay. Or consider the outgoing partygoer's chancy disposition; they will probably be very outgoing at the party, but they may not (McKitrick 2009: 190). Perhaps there are even what Hájek (2020) has recently dubbed "minkish dispositions", dispositions who might (rather than would) chancily fail to manifest in their stimulus conditions. Consider the wine glass that has a disposition to break when struck but might not break when struck on account of a merely chancy spot of structural strength.

Nevertheless, indeterministic, probabilistic, and minkish dispositions are still not the same things as abilities. The atom simply decays or not. The minkish wine glass will not break if it is struck on the chancy strong spot that just so happens to be strong when it is struck. And even if the normally outgoing agent just is not feeling the party, they can overcome their feelings. It's just they are not up for the party on this occasion, and this is not something that is up to them. So, even when dispositions are not surefire, I still want to say that the disposition manifested willynilly.

So, dispositions — be they simple, multitrack, surefire, or chancy—seem distinct from the kinds of abilities we are concerned with when theorize about free will. We can highlight this distinction by thinking about what dispositions and abilities do. Dispositions and abilities can both make a difference to what happens. However, there is apparently an important dissimilarity in the way that each can make a difference (cf. Nozick 1981: 311-313). Dispositions can make a difference insofar as some outcome would have been different if the disposition had not manifested. They can also make a difference insofar as their non-existence, absence, or their being interfered with would not bring about the same outcomes. ${ }^{13}$ But abilities can do more than

\footnotetext{
12 One might be tempted to define indeterministic dispositions as those dispositions whose manifestation may but needn't occur given the presence of the stimulus condition and the absence of intervening factors (cf. Clarke 2009: 326, ft. 3). But as an anonymous reviewer rightly pointed out, these dispositions could occur in deterministic worlds. Nothing in my argument that there is a gap between dispositions and abilities hangs on how we should precisely understand the nature of indeterministic dispositions.

${ }^{13}$ Sartorio (2005) argues that causation involves this kind of difference making.
} 
contribute to a change in outcomes given circumstances; instead, abilities are the origin of such changes. What settles that the fragile glass will break is not the glass itself-it is simply a matter of placing the glass in a condition in which its fragility manifests. Likewise, even with the minkish wine glass. In the right conditions, it simply might break. By contrast, by exercising an ability of the sort free will consists in, the agent settles what she will do. It is not merely a matter of the conditions she finds herself in. (Hence the apt spatial metaphor from the introduction). Agentive abilities, then, make a difference in this settling-specific way. ${ }^{14}$

In other words, there is a conceptual gap between our concept of dispositions on the one hand and our concept of agentive abilities on the other. The intuitively freedom-grounding aspect of these abilities - that they are the medium by which free agents settle what they well do- seems missing from dispositions. So, this aspect of these abilities seems unexplainable by dispositions as a suggested reductive base. Call this the gap problem. One need not endorse any strong conceptual constraints on successful reduction in order to advance the gap problem. It's just that dispositions seem either wrong as an analysis of abilities altogether, or deeply ill-suited to explain them. ${ }^{15}$ One might think that the gap problem poses a serious problem for any reductive analysis of the free

\footnotetext{
14 Some, like Mele (2017), demand clarity about how one settles what they do in the context of the disappearing agent objection to event-causal libertarianism. Say that I am deciding on what flavor of ice cream to buy. Following McKenna and Pereboom (2016: 238), I say that you settle which flavor-buying decision- deciding to get butter pecan instead of chocolate-by settling on butter pecan. A candidate view of the free will ability is an elucidation of how an agent goes about settling. For instance, to say that free will consists in the reasons-responsive ability is to say that an agent settles what she is going to do insofar as she is able to recognize and reacting to a suitable range of reasons. Settling, then, is the prior notion, one that could plausibly be basic in giving a theory of free will. Obviously not everyone will agree with this characterization. As I say below, the difference between dispositions and the kinds of abilities at issue in the free will debate to turn on an intuitive desideratum on a theory of free will, that it explain how a free agent has the control to settle what they are going to do. The problem then is best understood as a burden shift driven by, as a matter of methodology in metaphysics, taking this intuitive desideratum seriously.

15 Clarke (2009: 338-339, 2015: 901) and Vetter (2019) each point to a similar problem. Clarke suggests that having many kinds of abilities, and in particular the ones at issue in the free will debate, cannot simply be a matter of having a disposition (or bundle of dispositions). Abilities involve both underlying competencies (plausibly construed as dispositions) but also something more. When it comes to the abilities at issue in the free will debate, perhaps this something more is the choice to exercise them. So, dispositions are necessary but not sufficient for having the sort of abilities at issue. Vetter argues that dispositionalists "fail to classify a range of important exercises as exercises of abilities" (2019: 07). Drawing examples from Steward (2012), she points to sub-intentional actions, like scratchings, and complex habits, like riding a bicycle, as instances of action that do not depend on the kinds of basic actions that tend to feature in dispositional analyses of abilities, like tryings (or decidings or choosings). The gap problem is a distinct worry from either Clarke or Vetter's, but it explains why Clarke and Vetter are each right. Abilities make a difference in a way that dispositions do not. Thanks to an anonymous reviewer for pointing me in the direction of Vetter's paper.
} 
will ability. So, it poses a problem for reductive accounts of the free will ability as the ability to respond aptly to reasons in terms of dispositions. I will develop this problem in the form of a dilemma in the next section.

\section{The Dilemma}

I suspect that some compatibilists will not be moved by the gap problem as stated. Reductive compatibilism reduces abilities to dispositions by invoking what I will call active dispositions as the reductive base: dispositions that involve the activity of the agent. By contrast, we could think of fragility as a mere or passive disposition, a disposition whose elements are not agent-involving in this way. Reasons-responsive compatibilists typically reduce the ability to respond aptly to reasons to these kinds of active dispositions. Consider the plausible idea that van Inwagen's French-speaking agent does so because she has a disposition to choose to speak. French. (Or a disposition to choose whether to speak at all, or any number of agent-involving dispositions). One might think that, surely, an agent settles that they speak French by way of such dispositions! Thus, the reductive view has not failed to explain anything about the kinds of abilities that constitute free will. ${ }^{16}$

I'll argue that this will not suffice. What is it to be disposed to choose to speak French, or to be disposed to speak French when one tries to? Let's characterize the reductive view of the free will ability as the view that all there is to having agentive abilities is to have active dispositions (of a particular sort). But agentive activity cannot feature in either the stimulus conditions or the manifestation of a disposition without losing the intuitively freedom-grounding element of abilities. What do I mean by "agentive activity"? Well, we could think about an agent's activity in terms of her exercising her abilities as either the stimulus or manifestation of a disposition, e.g., to exercise an ability to choose. We could instead think of an agent's activity simply in terms of the performance of an action, e.g. ,to make a choice. An agent's action could be either the stimulus or manifestation of a disposition (or both). No option-neither activity as manifestation, either

\footnotetext{
16 Thanks to an anonymous referee for raising this worry, and pushing me to clarify these points about how an agent's activity can feature in the reductive dispositional analysis of abilities.
} 
as the exercise of an ability or as the performance of an action, nor activity as stimulus, either as the exercise of an ability or as the performance of an action-will work for the reductive compatibilist. Reducing abilities to dispositions to act runs afoul of the gap problem, whereas reducing abilities to dispositions to perform abilities does not secure the kind of reduction that would show how the free will ability is compatible with determinism, robbing the compatibilist of the motivation to go in for a reductive view in the first place.

Let's consider the first horn. One could offer an analysis of the free will ability in terms of dispositions where an agent's action is the manifestation of the disposition; for example, you could be disposed to choose on the basis of the reasons you recognize. But if so, then you do not settle what reasons you recognize, having no control over the antecedent stimulus conditions. Perhaps thinking of actions as manifestation is still not active enough. Consider again the plausible idea that an exercise of an ability itself could be the manifestation of a disposition. Problematically, however, this renders a purported analysis of the pertinent ability non-reductive. We cannot say that the kinds of abilities we wish to reductively explain are a part of our proposed reductive base. So, this kind of view does not secure what was compelling about the classical compatibilist strategy. Without a reduction, it is not clear that the ability invoked is compatible with determinism.

Now let's consider the other horn. One could offer an analysis where an agent's action is the stimulus conditions of the disposition; for example, you could be disposed to respond aptly to reason when you try to. Perhaps trying here is just the product of a prior disposition to try, and if so, then it looks like the agent does not settle for herself that she tries. If instead the prior trying is the exercise of an ability to try, then once again our analysis is not going to be reductive. ${ }^{17}$

So, neither option adequately captures what is freedom-grounding about the pertinent abilities, that they are that in virtue of which an agent settles what they are going to do, while remaining a reductive view of abilities of the sort a compatibilist wants.

\footnotetext{
17 One could plausibly read Michael Smith's $(1997,2000)$ and Michael Fara's (2008) views in this way.
} 
This dilemma undermines the compatibilist motivation for reductionism about abilities, namely, to offer a theory of how the free will ability could be compatible with determinism. I claim that this is because the pertinent agentive abilities, the ones in virtue of which an agent is free and so morally responsible, make a difference in a special way. I have characterized this special way terms of making a difference by settling. As a conceptual point, one can see how talk of settling might give rise to the thought that if determinism is true then no agent can ever make a difference in the settling-specific way. (Perhaps this question-begging thought lurks in van Inwagen's remarks). For all I've said, one might worry on behalf of reductive compatibilism that I am appealing to incompatibilist intuitions unfairly and so starting with a notion of control that is much stronger than compatibilists should accept (even if it does not entail the falsity of compatibilism) by casting the control needed to be morally responsible in terms of settling.

I will explore issues in greater detail in section 6, where I will show how a possible libertarian view would also face the gap problem and compare the gap problem to the disappearing agent objection to event-causal libertarianism. For now, note that this objection presupposes too much about the pertinent notion of settling. I take it that the pertinent notion leaves open the compatibility question. Having an ability does not necessarily mean one has a power to originate changes by settling on what to do in a way that simply requires that there are no antecedent sufficient conditions for whether or how one originates those changes. It's just that when an agent exercises her free will ability, she makes a differing by settling that such a change occurs, given the opportunity to do so.

How then should we understand the argumentative force of the gap problem, and the dilemma I am pushing against reductive compatibilists? I will invoke the idea of a neutral inquirer here, like many do in the free will debate, as a way of establishing argumentative burdens (e.g. Mele 2006, Pereboom 2008, McKenna 2014). ${ }^{18}$ The thought that there is some space between what

18 Thanks to an anonymous reviewer for helpfully suggesting this way of framing the gap problem. 
happens to us and what we do, the idea that free agents settle that such-and-such occurs, should strike a fair-minded neutral inquirer as an important and intuitive desideratum of a theory of the free will ability. I do not think such a neutral inquirer would count the failure to capture this desideratum as an outright defeater of a theory. Maybe the theoretical gains made by the theory outweigh the cost of failing the intuitive desideratum. Nevertheless, I want to give voice to the gap problem as a problem precisely because the apparent theoretical benefits of reductive compatibilism have obscured an important cost. The gap problem casts doubt on the idea that the pertinent abilities are nothing more than active dispositions, and so the view that free will is nothing more than reasons-responsive dispositions to act. As this reductive commitment is a central feature of the common reasons-responsive view, it is worth expressing this important cost.

In the immediate next sections, I will illustrate the different horns of the dilemma using two example views, one on each horn of the dilemma: Fischer and Ravizza's (1998) appeal to response-responsiveness and Kadri Vihvelin's (2013) dispositional conception of free will.

\section{Agentive Activity as Manifestation}

Consider the first way of proceeding, where one attempts to analyze the free will ability in terms of dispositions where the activity of the agent is the manifestation of the disposition. For instance, Fischer and Ravizza (1998: 62) seem to offer this kind of view. They work in terms of dispositions to recognize reasons and to choose in accordance with those reasons. ${ }^{19}$ This sort of view seems to animate the presumptive case in favor of reasons-responsive compatibilism, for these dispositions seem to capture agentive activity and are apparently compatible with determinism. One might be tempted to say that a view like this just shows that there is no gap problem at all. The view says there is no gap. There is nothing leftover or left out when we reduce.

Although at first it might seem that the gap problem disappears on such an account, I

\footnotetext{
19 They talk in terms of a "cognitive" power to recognize reasons and an "executive" power to choose. Both are general dispositions of an agent's mechanism of action rather than abilities of the agent. This executive power is explicitly cast in terms of reacting to incentives recognized by the cognitive power (1998: 75). The successful manifestation of the cognitive disposition is the stimulus for the executive one.
} 
worry that this just buries the issue. Dispositions manifest when the stimulus condition occurs, willy-nilly. This seems to be conceptually ill-suited to explain abilities insofar as the stimulus conditions prompt the manifestation of the disposition. The problem is that dispositions seem unable to highlight a sense of control moving through the processes of stimulus condition to manifestation. Consider dispositions to recognize reasons and choose in accordance with those reasons. First, we do not settle what reasons we recognize as such. And given this, our choices seem not to be settled by us either- that is, unless we have an ability to choose in response to our reasons. Notice that if this further ability is reduced to a further disposition to react to reasons, then we once again fall into the gap problem, rendering our reaction to reasons as something that we ourselves do not settle.

Isn't this a stretch? It might seem to some that the gap problem boils down to the idea that the stimulus conditions of a disposition are something done to the thing which has said disposition (like dropping a fragile glass). Dispositions seem to involve a kind of passivity on the part of the disposed. Actions, on the other hand, originate from the agent. If one thought that this was the heart of the gap problem, one might reply like this. It is important that the agent's reasons are the stimulus conditions for my choosing. Why? They are internal to the agent (cf. Clarke 2015: 898, Vihvelin 2013: 172). It is not as if something outside of the agent is pushing her around! This makes an active disposition to respond to reasons rather unlike a disposition like fragility. Indeed, these active dispositions seem to be tracking an internal locus of control on the part of the agent.

Fair enough. The gap problem is neither about the external conditions of action nor about the agent's lack of activity, however. The problem as I understand it is about explaining the right kind of activity, the sort difference-making which characterizes the freedom-grounding aspect of abilities. The free will ability is typically understood to be an ability to perform a basic action, an action we can take without doing something else. These are typically understood to be abilities to choose, decide, or try. Hence, we can be directly in control of and responsible for the performance 
of basic actions like choosing, deciding, or trying. ${ }^{20}$ But which reasons I recognize is not a matter of my taking a basic action by deciding, choosing, or trying. (At least not directly). So, nothing about the stimulus condition of my dispositions to choose in response to the reasons I recognize is a matter of my taking a basic action. And if my choosing in accordance with the reasons I recognize is the (willy-nilly) manifestation of a disposition, then it looks like I do not settle the matter of what I do. An agent's reacting to the reasons which she recognizes cannot be a mere reaction to background conditions. ${ }^{21}$

To close the gap, we need the right sort of activity to feature in the pertinent dispositions. Otherwise, they will be mere dispositions. Plausibly, though, the right kind of activity, the kind of activity that would ground an agent's freedom, is just the exercise of an ability in response to her reasons, like an ability to choose. Exercises of abilities do not happen willy-nilly. They do not happen irrespective of an agent's performing a basic action. ${ }^{22}$ So now it looks like we will have to invoke the exercise of an ability as the manifestation of the disposition to respond to reasons. If so, then these dispositions cannot be a suitable reduction base for the pertinent abilities. They involve abilities! Indeed, if we have said nothing about the nature of these abilities to choose, then perhaps they require the falsity of determinism. If so, then we cannot marshal this kind of reductive analysis as part of the case in favor of compatibilism.

\section{Agentive Activity as Stimulus}

Reductive reasons-responsive compatibilists will have to try something different. Let's consider the other kind of account that a reasons-responsive compatibilist might offer, which reduces abilities to active dispositions where the pertinent activity is in the stimulus condition of the disposition.

\footnotetext{
${ }^{20}$ For instance, Pereboom (2001: xxi) suggests that freedom and responsibility apply to decisions.

${ }^{21}$ Switching to an agent-based reasons-responsive theory (e.g. McKenna 2013) won't resolve this problem. If we characterize the agent's reasons-responsiveness in terms of dispositions, then we seem committed to her (willy-nilly) responding to a condition which was not settled by herself.

22 An initial gloss of "irrespective of the agent" might read "whether the agent likes it or not", but as a referee helpfully pointed out, perhaps the pertinent manifestation of the disposition involves doing as one likes! The more apt comparison is again to an ordinary disposition like fragility. The fragile glass will simply break when dropped.
} 
I will use Vihvelin's (2013) view as an example. Vihvelin sees herself as offering an account of active dispositions to act in intelligent and goal-directed ways. Indeed, she distinguishes between the pertinent active dispositions and mere dispositions like fragility, solubility, and the like (2013: 178). She maintains that the free will ability is the narrow ability to choose on the basis of reasons. Extrapolating from her analysis of abilities as dispositions, this narrow ability consists in being disposed to choose on the basis of reasons. These choices need occur only in a suitable proportion of cases where one has an opportunity to choose on the basis of reasons, has some intrinsic causal basis for this ability, and tries to choose on the basis of reasons (2013: 187). This seems to capture the right kind of activity. Why? The "tries to choose" condition of the analysis here is important. For it allows the agent to settle the stimulus condition of the disposition to respond aptly to reasons. This gets around the problem for views that only locate the relevant agentive activity in the manifestation condition.

You will notice that this is a sophisticated version of the failed classical compatibilist conditional analysis of abilities cast in terms of dispositions rather than counterfactuals. Recall that such views were extensionally inadequate and so couldn't motivate compatibilism. Vihvelin rightly has a more modest aim in mind. Her dispositional account is meant to "fill in the details" of a compatibilist conception of what abilities ground the facts of freedom within a commonsensical picture of free agency (2013: 214). ${ }^{23}$ Dispositions are supposed to explain why the free will ability is compatible with determinism not show that it is so. ${ }^{24}$

Still, if the modest aim of offering a compatibilist-friendly analysis of abilities fails by way of the gap problem, a fortiori so too does the less modest aim of employing such an analysis as part of the case for compatibilism.

\footnotetext{
${ }^{23}$ Vihvelin does not offer an analysis in the sense of giving necessary and sufficient conditions. Rather, she thinks of herself as offering an analysis vis-à-vis plausible ontological reduction as a kind of research program for compatibilists (2013: 170).

${ }^{24}$ In spite of my criticism, I am sympathetic to Vihvelin's defense of commonsense, compatibilism. She rightly claims that the issue of determinism is orthogonal to what ordinary people mean when they say that they have abilities and opportunities. I only worry about her treating abilities like dispositions.
} 
This modern, modest take on the classic strategy won't work, unfortunately. It faces the same difficulties as its forerunner. It turns out that these difficulties are in fact explained by the gap problem.

Chisholm (1964) articulated the following challenge to the classical conditional analysis. The classical analysis is supposed to tell me whether or not I could do otherwise. It says I can do otherwise when, if I had tried to do otherwise, I would have. But a trying to do otherwise is just an instance of doing otherwise, because a trying is itself a doing. It is a particular kind of doing, a mental action, and a basic action at that. Trying is plausibly an action we can take without doing something else. Hence, it is the sort of thing we can have direct control over and be directly responsible for. The ability to try is therefore, plausibly, an ability to perform a basic action. This is the sort of ability which might be the free will ability. And I may or may not be able to try. To parrot Davidson's (1973: 114) understanding of the argument: the antecedent of the pertinent conditional must not contain any verb which makes sense of the question: can someone do it?

In order for the analysis to be informative, then, it must assume that I am able to try. That I am able to try is exactly the kind of question we ought to be answering in the free will debate, and unfortunately, it has gone unexplained. Indeed, the counterexamples to the classical analysis are just cases where an agent cannot try to do something, but nevertheless, if she were to try to do it, she would (e.g. Lehrer 1968). Thus, the agents in the counterexamples appear unable to perform the action in question.

In other words: the classical analysis appeared informative only because it assumed that an agent could perform a basic action, a trying or the like. There are, after all, many actions we can take only because we try. However, the classical analysis offers no answer to the question: is the agent able to try? The analysis therefore does not rule out that indeterminism is part of what it takes to be able to try. It is simply silent on the matter.

The same challenge faces dispositional accounts of abilities that involve basic actions in the stimulus condition. Recall that (simplifying a good deal) Vihvelin's analysis reduces the ability 
to respond aptly to reasons to a disposition to respond aptly to reasons when one tries to choose on the basis of reasons. Analyses of the free will ability are supposed to tell us what it means when we say I am able to try to do things. They cannot presuppose that I am able to try in order to be informative. And it looks like Vihvelin's take on the classical strategy does so. It doesn't tell us what it means for an agent to be able to try to choose. In her case, the problem is also related to a purported extensional failure. Clarke (2015: 896) has suggested that Vihvelin's analysis fails by counterexample in cases where the intrinsic causal basis of an ability will be lost were the agent to try to exercise it.

Perhaps these objections are mistaken. The agent in the counterexamples cannot try to do the target action. Nevertheless, there is a sense in which she is able to perform the action. Why? If she were to try to, she would succeed, just as this kind of reductive analysis suggests (cf. Vihvelin (2013: 201-203).

I remain unconvinced. Reflecting on the gap problem clarifies that the sense in which the agent in the counterexamples remains able to do things is not the pertinent sense. The reductive analyses leave open the possibility that the exercise of some of an agent's abilities (that is, that they are exercised) could fail to be settled by the agent herself. This is just a failure to explain the aspect of agentive abilities that seem to ground an agent's freedom and responsibility. To exercise this sort of ability is to make a difference by settling that some action occurs given the opportunity to do so.

In general, a proponent of this sort of analysis— the sort where we take agentive activity to the stimulus condition of the disposition to act-has two options when it comes to performing basic actions like trying. Let's construe a trying as the acquisition of an intention or desire to do something that is causally efficacious in beginning the process of doing something goal oriented (Vihvelin 2013: 176). ${ }^{25}$ Well, either the agent settles that she acquires a causally efficacious intention

${ }^{25}$ As an anonymous reviewer pointed out, trying often involves performing complex bodily actions, and it seems like the simple fact of acquiring an intention or forming a desire is not sufficient for trying. Vihvelin's way around this problem, which strikes me as the plausible strategy, is to count as tryings causally effective initiators of complex 
or desire, or she doesn't. ${ }^{26}$ In the first case, the proponent of the analysis cannot invoke an unexplained ability to try (or choose, or decide) to try, in virtue of which the agent settles that she tries. And if the proponent explains this ability to try to try as a disposition to try when one tries to, then we can simply reiterate the problem. When is an agent able to try to try? On the other hand, if the proponent instead argues that a trying can initiate from a process which the agent herself does not settle, then I say this process is not control-implicating. The trying isn't settled by the agent herself. (An agent doesn't settle that she tries when a trying is caused by an overwhelming and unendorsed desire, for instance).

We should conclude that this kind of analysis cannot plausibly explain what the pertinent reasons-responsive abilities are. Given this, they cannot offer a plausible compatibilist view of how free will could be compatible with determinism.

\section{Two Objections Considered and a Note on a Family Resemblance}

So far, I have argued that reductive analyses of the free will ability in terms of dispositions face an intuitive gap between the reducing entity and the reduced one, using reasons-responsive abilities as an example. One way to deal with this gap makes it such that an agent's actions are not settled by the agent herself. The other way presupposes that agents have abilities of the sort which are plausible candidates themselves for free will. These analyses therefore fail. Since they fail, they cannot be put to work in favor of compatibilism. (They could, however, feature as partial characterizations of the free will ability in a compatibilist view. More on this shortly).

Skeptical readers will still have been worrying that the gap problem begs the question against compatibilism, and after setting out the argument and working through two examples, I can now answer their skepticism. Vihvelin herself gives voice to this worry in a particularly clear

\footnotetext{
sequences of goal-oriented action. Basic actions that count as tryings will likely involve one's reasons for action, like the weighing of one's reasons. But now we have to ask if this weighing is the exercise of an ability or the manifestation of a disposition, and hence, we run into exactly the sort of explanatory issue the gap problem raises for a view like Fischer and Ravizza (1998), as discussed in section 4.

26 Vihvelin offers a defense of both options. She can consistently do so because she holds the view that a process counts as a trying if it causally leads to the beginning of an action. Such a process may or may not be initiated by an agent's trying to try (2013: 176-180).
} 
way. She suggests that van Inwagen appears committed to the claim that "the concept of a disposition is the concept of something that is compatible with determinism whereas the concept of an agent's ability or power to act is the concept of something that is incompatible with determinism" when he distinguishes abilities from dispositions (2014: 173). If this were so, then van Inwagen plainly begs the question. Perhaps I do too.

I don't, though. I have defended no principle which entails the falsity of compatibilism. Indeed, I have argued that the gap problem extends to dispositions that are indeterministic or chancy. Perhaps it looked like I begged the question since an upshot of my view is that an adequate account of the free will ability looks more friendly to libertarians than compatibilists have generally recognized, since libertarians have less reason to adopt reductionism about abilities. They do not have the reason to reduce for the sake of explaining how free will could be compatible with determinism. Nevertheless, there are possible libertarian reductive accounts of the free will ability in terms of indeterministic dispositions. And the gap problem is in principle generalizable to these views. Since there are to my knowledge no libertarian accounts of free will of this sort, what I hope to show by sketching a possible libertarian view is that the gap problem does not beg the question against compatibilists. ${ }^{27}$

\footnotetext{
${ }^{27}$ Although I know of no libertarians who offer explicitly reductive accounts of the free will ability in terms of indeterministic or chancy dispositions, it is generally assumed that you can get an event-causal libertarian view by taking an event-causal compatibilist view and inserting indeterminism into the causal chain at the right moment. And the reductive, reasons-responsive compatibilist views we have been considering are indeed event-causal. This suggests that it is possible that some extant libertarian accounts of free will also are caught up in the gap problem in terms of dispositions, and the dilemma it poses. Here's how. Randolph Clarke (2000: 21, 22) characterizes a modest eventcausal libertarian view as one that starts from the assumption that agents have "an ordinary capacity to engage in practical reasoning", and who agrees with the compatibilist "that agent's having and being able to exercise a capacity for rational-self-governance" but insists that some causation in the causal process that leads to action must not be deterministic. What are these capacities? Perhaps they are dispositions. Perhaps it is plausible, then, to think that the gap problem extends to event-causal libertarian views that unreflectively assume the standard reductive compatibilist commitments I believe fail due to the gap problem, and the dilemma that ensues from it. Are there unreflective eventcausal libertarians? I am doubtful. My sense is that contemporary event-causal libertarians will either not offer full reductive analyses of the free will ability, like Franklin (2018), who offers a partial analysis of abilities, or simply not appeal to abilities in offering their views, perhaps like Ekstrom (2019)—see footnote 34. As a historical note about the origins of the gap problem, it is worth pointing out that van Inwagen himself nearly takes the notion of human ability as a fundamental when he rejects classic dispositional accounts of abilities (1983: 9-10). This makes sense. If you thought that the important freedom-grounding element of free will was indeterminism, you would not worry so much about appealing to (and then reducing) abilities to something that was compatible with determinism, like dispositions. However, like Dana Nelkin (2012: 75), I think that a focus on indeterminism mislocates what is special about free will.
} 
To briefly recap the gap problem in terms of indeterministic dispositions: there is a difference between the radioactive atom that has an indeterministic disposition to decay or not decay, and the ability of an agent to speak French or not. For there is surely no sense of control on the part of the atom in whether or not it will decay, whereas one elects if and when to speak. And this is because the stimulus condition of the atom's decay does not provide an opportunity. The stimulus could trigger a reaction, or it could not. Conversely, if an agent exercises her ability to speak French, she had an opportunity to do so. Moreover, she settles that she speaks. If you are a libertarian, you may think she settles this because nothing antecedently determined her to do so.

Can our libertarian close this gap between indeterministic dispositions and abilities? No. Here again we have the dilemma. Let's say that she offers a simple view like this: the free will ability is the indeterministic disposition to choose in response to reasons. The problem here is that she does not settle the reasons she recognizes. And her choice cannot be a mere reaction to her reasons. A reaction is still a reaction, even when it is not determined to happen given prior conditions. If she does settle her choice in response to reasons, then, it seems to be because she exercised some ability.

What if the libertarian says instead that the free will ability is the indeterministic disposition to choose when one tries on the basis of reasons? Now we have run into the other problem. Aren't we trying to explain abilities to perform basic actions like trying? We can't presuppose an unexplained ability to try.

In brief: the gap problem does not beg the question against the compatibilist. It is a general problem about reductionism in the metaphysics of abilities. So, the gap problem is legitimate and poses a serious problem for reductive accounts of the reasons-responsive ability (and of the free will ability in general).

But maybe the gap problem begs the question against reductionism about free will. Well, none of the foregoing entails that other reductive compatibilist projects, ones that are not based around dispositions, will fail. What might these alternatives look like? 
They mustn't look very much like the kind of reductive compatibilism I've considered above. The gap problem seems to remain even when we change the underlying metaphysics from disposition to something else. As an example, consider a reductive compatibilist project based on causation and not on dispositions. One way to secure the compatibility of some agency-relevant ability and determinism is to reduce that ability to patterns of causation. Alfred Mele's compatibilist proposals could be construed in this manner. In his (1995: 193), free action critically involves the nondeviant production of action on the basis of rationally formed deliberative judgment. "On the basis of" seems not uncharitably construed as a causal notion. (In any event, one might neatly adapt his proposals in this manner). ${ }^{28}$

The worry for the reductive strategy in terms of dispositions is that it failed to account for the freedom-grounding element in our concept of a free agent's ability. There is a "space" between what happens to us and what we choose to do within which agents can make a difference by settling what comes next. Now, if our abilities are to be successfully reduced to causal relations, then I fear we will once again lose the freedom-grounding element in our concept. There is no "space" between causes and effects. Causes are not opportunities for effects; effects are not elected.

A compelling way to get around this new gap would be to reduce abilities to patterns of causation, and then (perhaps) reduce causation to pertinent counterfactuals (cf. Lewis (1973). But now we face a dilemma. A plausible way of developing this idea would be to put the agent's activity in either the causes or the effects. If in the effects, then it is no longer clear that it is the agent who settles what she is going to do. If instead the activity is in the causes, then just like putting activity in the stimulus condition of a disposition, we risk presupposing what we aim to explain or failing to explain it altogether. The second horn of this dilemma essentially echoes Chisholm's (1964)

\footnotetext{
${ }^{28}$ See Mele (2006: 170) for another example.
} 
criticism of the classical compatibilist view. If we say an ability involves an agent's trying or deciding as a cause of action, well, what causes the agent to try or decide?

The problem on the other horn, of putting activity in the effects, is old too. Davidson (1973) suggested a way around Chisholm's problem for the classical compatibilist view: move the action verb to the consequent of the conditional and place plausible causal conditions of intentional actions into the antecedent. Davidson (ibid.: 148) suggests this: "A can do $x$ intentionally (under the description d) means that if $\mathrm{A}$ has desires and beliefs that rationalize $\mathrm{x}$ (under d), then A does x."

But Davidson finds this causal fix problematic in a way that echoes the problem on the first horn of the dilemma (1973: 154-155). Deviant causal chains prevent us from saying that if an agent's desires and beliefs rationalize $\mathrm{x}$ then he does $\mathrm{x}$ intentionally. An agent's beliefs and desires may directly cause the rationalized action. Davidson's example is a climber who, in order to survive, needs to let go of a rope holding up a fellow climber. She is so unnerved by this thought that she slips up and drops the rope without meaning to. The analysis wrongly says that she acted intentionally Now, There is a compelling tradition of thinking about deviant causal chains in action theory that says our intentions (or other relevant psychological states) guide unfolding action in a way that resolves the deviance problem (e.g., Brand 1984, Mele and Moser 1994). Davidson is concerned with action, whereas I am concerned with free (and do so morally responsible) action. But notice that the agent herself does not settle that she is in fact unnerved, and that a simple Davidson-style reductive analysis of the free will ability in purely causal terms would wrongly suggest that she intentionally acted, and so settled that fact. I suspect that a more complex appeal to guidance will not avoid this basic problem (although much more could be said about this).

Readers conversant in debates concerning libertarianism might now notice some similarities between the gap problem and the disappearing agent objection to event-causal libertarianism (Pereboom 2014; Levy 2008, 2011; Waller, 2011). As Pereboom (2014: 60-61) puts his version of disappearing agent objection, if there is no antecedent agent-involving event that 
determines which course of action the agent will take, the agent does not really settle what they are going to do, and so the agent "disappears" from the very explanation of how the agent is free. Pereboom goes so far as to say that on the event-causal libertarian theory, nothing settles that a decision to act occurs. Is this just the gap problem for libertarians? ${ }^{29}$

No. The gap problem is similar in form to this objection, but they are distinct. ${ }^{30}$ They have ancestral feature, namely an appeal to the intuitive idea that a free agent settles for herself what she is going to do. But each develops this appeal in different ways. The event-causal libertarian suggests that an agent is free in virtue of a non-determined event-causal process, and the objector suggests that agents cannot settle what they do in virtue of such a casual process without disappearing, so to speak. The gap problem is related to but distinct from the disappearing agent objection, insofar as the gap problem concerns reductive explanations of free will in terms of abilities. The views under consideration in this paper suggest that agents have free will in virtue of abilities, understood reductively in terms of dispositions (or causal sequences), and my objection is that agents cannot settle what they do in virtue of these things. The problem is not that the agent disappears from the pertinent explanation of free will—the reductive compatibilist view under discussion focuses on what I have called "active dispositions", which involve the activity of the agent.

\footnotetext{
${ }^{29}$ Here again we might consider how actual libertarian views interact with the gap problem. Mele (2006, inter alia) is a well-known agnostic about the free will problem, advancing both compatibilist and libertarian theories of free agency. Perhaps the libertarian version of his view will face the gap problem. But in general, it is harder to say exactly what libertarians should think about reducing abilities to causal sequences. Let me explain with a recent example. Laura Ekstrom (2019: 141) seems to endorse a kind of reductionism about abilities when she says that "events-the occurrence of certain of an agent's attitudes, which are considerations relevant to the decision-cause the event of the decision; that is what it is for an agent to exercise her ability to make a decision for reasons." But in saying so, she is responding to the disappearing agent objection as Pereboom advances it, and so it seems charitable to think she is downplaying the explanatory role of abilities rather than adopting the strong version of reductionism about abilities that I am targeting in this paper. This would suggest that many event-causal libertarians have a somewhat analogous view to that of Carolina Sartorio (2016), whose I describe as advancing an "ability-neutral" view in the next section. $30 \mathrm{My}$ sincere thanks to an anonymous referee for pointing this out. Disappearing agent objections are related to a more general worry with event-causalism as a reductive theory of agency. On an event-causal framework, where events are fundamental rather than agents, one might worry that there seems to be no agent settling anything at all, but rather, only agent-involving events (Velleman 1992, Mele 2003, Steward 2012). One way to persuasively respond to this problem is, like Mele (2003), to characterize it in terms of "shrinking" agency and show how an event-causal account can explicate agency par excellence, agency that has all the features we want it to. I am inclined to think that part of agency par excellence is apt description of agency in terms of abilities and believe that these descriptions are consistent with both agent-causal and event-causal frameworks.
} 
Notice too that if the disappearing agent objection succeeds, the option left for the libertarian theorist of free will seems to be agent-causalism. By contrast, the gap problem is neutral with respect to the ontology of agents. It has implications for the ontology of abilities, nevertheless, which I will explore in the next section. Indeed, one way to mark the difference between the two objections is to note that an event-causal libertarian can appeal to an agent's abilities to secure an appropriate agent-inclusive explanation. In responding to Pereboom's objection, as Christopher Franklin, a reductive event-causal libertarian, persuasively does (2018: 178). Franklin suggests that it is because of an agent's abilities and opportunities that they settle what decision they will make that given antecedent events. And this is a very natural move to make: it is, intuitively, in virtue of certain kinds of abilities that an agent has free will because it is in virtue of those abilities that an agent settles the decisions they are going to make. So, we have an agent-involving explanation because the agent has abilities. Importantly, Franklin can make this move because he does not endorse a reductive analysis of abilities, but only advances a partial analysis consistent with his event-causal framework (2018: 67-69). (I will suggest that compatibilists adopt a similar line about abilities momentarily in response to the gap problem).

\section{Two Options Explored}

The foregoing objections and the comparison to the disappearing agent objection highlights the lesson of the gap problem. The problem with the compatibilist accounts of free will under consideration is not reductionism per se, but rather reductionism about the abilities in virtue of which we have free will. In this section, I will suggest that compatibilist adopt one of two strategies instead of the commonplace reduction of abilities to dispositions.

Here is one promising alternative. A commitment to abilities could be given up consistent with a kind of reductionism about free will (and with a reasons-responsive approach to freedom). Carolina Sartorio (2016) argues that the freedom of an agent is grounded in the reasons, and crucially the absence of other reasons, given a suitably wide range of reasons, that are the causes of her action in the actual sequence of events. She goes on to argue that there is "no difference in 
freedom without a difference in the relevant elements of the causal sequence" (2016: 32). Notice that there has been no mention of abilities so far. Her view can be developed in an ability-neutral way. Maybe the relevant abilities supervene on the actual sequence, but they would not be explanatorily basic. Freedom is instead explained directly in terms of causation by reasons. It is arguable that supervenience suffices for reduction, and so such a view retains a commitment to the reductive compatibilist project.

This is promising, but I have reservations. For those of us who would like to respond to the traditional problem of free will, the problem of reconciling some special freedom-grounding ability with the thesis of physical determinism, this may be asking too much. A successful account of freedom does seem at least a little beholden to the traditional (and intuitive) view, that if we are free and responsible, it is in virtue of some special ability characteristic of free agents. I take the rejection of this set up to be a cost to the view. Of course, though, the theoretical power of Sartorio's proposal follows by denying precisely what I take to be the intuitive grounding claim. And many will find Sartorio's suggestion intuitive, as it builds on longstanding ways of understanding the nature of action in terms of causes. Compatibilists should consider the abilityneutral alternative carefully.

What about those of us who think abilities need to play a critical explanatory role? There is another option worth considering. Susan Wolf (1990) rejects the need for a reductive analysis of abilities. She instead supplies a "characterization of what is involved in attributing an ability to someone" in terms of the skills, talents, and so on necessary for having it. Such a characterization purports to show the "per se irrelevance" of determinism to an agent's having abilities (1990: 101). Nelkin (2013) and McKenna (2019) have both recently argued for similar views of the reasonsresponsive ability. On this kind of view, the free will ability is not identified with dispositions. Instead, the relevant dispositions (and related counterfactuals) provide forensic evidence about the existence and nature of the ability. Critically, this evidence is taken to show that the ability is compatible with determinism. How so? This evidence helps us understand when and why an agent 
is able or unable to act in particular situations. For instance, if a disposition required to exercise some ability is impeded in some manner, we can infer that they are unable to exercise that ability. Arguably, these dispositions are not impeded by determinism. So, we have reason to think the abilities are not impeded either. This sort of view, then, does not offer a complete theory of the pertinent abilities, but rather, a partial and compatibilist-friendly characterization of them. I note that Nelkin is an agent-causalist and McKenna is an event-causalist; this non-reductive approach is consistent with both ontologies of agency.

By my lights, this approach is to be preferred over the abilities-neutral alternative. The strategy, however, is at best, a burden shift. Even though the dispositions needed to exercise our freedom-relevant abilities are indeed a kind of forensic evidence about those abilities, this evidence does not resolve the relevant question. We have no evidence that dispositions (or skills or talents and so on) needed to have an ability exhaustively capture the essential freedom grounding elements of that ability. It is quite possible that some further element needed for having and exercising that ability is not compatible with determinism. Since the view offers no evidence to the contrary, it offers no full answer to the compatibility question. Of course, having no full answer is not the same as having no answer at all. Compatibilists should consider this ontologically "liberal" approach to abilities carefully too (McKenna 2019: 23).

\section{Conclusion}

Reductive compatibilism faces a serious challenge. There is a gap between our intuitive ideas about abilities and the metaphysical notions, compatible with determinism, that we might appeal to in reductively explaining the nature of these abilities. The lesson was this: compatibilists can either keep a commitment to reductionism about free will or keep a commitment to the grounding claim about freedom in terms of abilities. They cannot keep both. This problem has not been sufficiently recognized, and so it has not been aptly responded to. 


\section{References:}

Ayer, A. J. 1954. "Freedom and Necessity." Philosophical Essays. New York: St. Martin's Press: 320.

Brand, M. 1984. Intending and Acting. Cambridge, MA: MIT Press.

Chisholm, R. 1964. "Human Freedom and the Self". Reprinted in Chisholm, Roderick. 1989. On Metaphysics. Univ. of Minnesota Press.

Clarke, R. 2015. “Abilities to Act”, Pbilosophy Compass. 10(12): 893-904. . 2009. "Dispositions, Abilities to Act, and Free Will: The New Dispositionalism." Mind. 118(470): 323-51. .2000. "Modest libertarianism." Philosophical Perspectives 14: 21-45.

Davidson, D. 1973. "Freedom to Act". in Ted Honderich (ed.), Essays on Freedom of Action. Routledge.

Ekstrom, L. 2019. “Toward a Plausible Event-Causal Indeterminist Account of Free Will.” Synthese 196: $127-144$.

Fara, M. 2008. "Masked Abilities and Compatibilism.” Mind 117(468): 843-65.

Fischer, J.M., and M. Ravizza. 1998. Responsibility and Control: An Essay on Moral Responsibility. Cambridge: Cambridge University Press

Franklin, C. 2018. A Minimal Libertarianism: Free Will and the Promise of Reduction. New York: Oxford University Press.

Hájek, A. 2020. A. "Minkish Dispositions.” Synthese 197: 4795-4811

Lehrer, K. 1968. “Can's Without 'If's.” Analysis 24: 159-60.

Levy, 2011. Hard Luck: How Luck Undermines Free Will and Moral Responsibility. New York: Oxford University Press 2008. "Bad Luck Once Again”. Philosophy and Phenomenological Research 77(3): 749-754.

Lewis, D. 1997. "Finkish Dispositions.” The Philosophical Quarterly. vol. 47. 187: 143-158. 1973. "Causation," Journal of Philosophy 70: 556-567.

Manley, D. and R. Wasserman. 2007. "A Gradable Approach to Dispositions." The Philosophical Quarterly, vol. 57. 226: 68-75.

Martin, C.B. 1994. "Dispositions and Conditionals." The Philosophical Quarterly 44(174): 1-8.

McKenna, M. 2019. “Watsonian Compatibilism.” In Oxford Studies in Agency and Responsibility, Justin Coates and Neal Tognazzini, eds. Vol. 5.

2014. "Resisting the Manipulation Argument: A Hard-liner Takes it on the Chin." Philosophy and Phenomenological Research: 89: 467-84.

. 2013. "Reasons-Responsiveness, Agents, and Mechanisms." In David Shoemaker, ed., 2013. Oxford Studies in Agency and Responsibility, vol. 1. Oxford: Oxford University Press: 15184.

. 2008 "Ultimacy \& Sweet Jane." In Nick Trakakis and Daniel Cohen, eds., 2008. Essays on Free Will and Moral Responsibility. Cambridge Scholars Publishing: 186-208.

McKenna, M. and D. Pereboom. 2016. Free Will: A Contemporary Introduction. New York: Routledge.

McKitrick, J. 2009. "Dispositional Pluralism.” in Debating Dispositions: Issues in Metaphyscis, Epistemology and Philosophy of Mind, ed. Gregor Damschen, Robert Schnepf, and Karsten R. Stüber. Berlin \& New York: Walter de Gruyter: 186-203. 
Mele, A. 2017. “On Pereboom's Disappearing Agent Argument". Criminal Law and Philosophy 11 (3):561-574. 2006. Free Will and Luck. New York: Oxford University Press. 2003. Motivation and Agency. Oxford: Oxford University Press. 1995. Autonomous Agents. New York: Oxford University Press. 1992. Springs of Action. New York: Oxford University Press.

Mele, A. and Moser, P. K. 1994. "Intentional Action" Nous 28: 39-68.

Moore, G. E. 1912. Ethics. Oxford: Oxford University Press.

Nelkin, D. 2011. Making Sense of Freedom and Responsibility. Oxford University Press.

Nozick, R. 1981. Philosophical Explanations. Cambridge, Mass: Harvard University Press.

Pereboom, D. 2014. Free Will, Agency, and Meaning in Life. Oxford: Oxford University Press.

2008. "A Hard-line Reply to the Multiple-Case Manipulation Argument." Philosophy and Phenomenological Research 77 (1): 160- 70. 2001. Living Without Free Will. Cambridge: Cambridge University Press

Prior, E., R. Pargetter, and F. Jackson. 1982. "Three Theses about Dispositions." American Philosophical Quarterly 19: 251-257.

Sartorio, C. 2016. Causation and Free Will. Oxford: Oxford University Press. . 2005. "Causes as Difference-Makers." Philosophical Studies 123(1): 71-96.

Schlick, M. 1939. "When is a Man Responsible?” In Schlick, Problems of Ethics Prentice-Hall: 14356.

Smith, M. 2003. "Rational Capacities, or: How to Distinguish Recklessness, Weakness, and Compulsion." In_Weakness of Will and Practical Irrationality. Eds. Sarah Stroud \& Christine Tappolet. Oxford: Clarendon Press: 17-38. . 1997. "A Theory of Freedom and Responsibility." In_Ethics and Practical Reason. Eds. G Cullity \& B Gaut. Oxford: Oxford University Press: 293-317.

Steward, H. 2012. A Metaphysics for Freedom. Oxford: Oxford University Press.

van Inwagen, P. 1983. An Essay on Free Will. Oxford: Clarendon Press.

Vargas, M. 2013. Building Better Beings. Oxford, UK: Oxford University Press.

Velleman, D. 1992. "What Happens When Someone Acts?” Mind 101(403): 461-481.

Vetter, B. 2019. “Are Abilities Dispositions?” Synthese. Vol. 196: 201-220 . 2013. “'Can' Without Possible Worlds”. Philosopher's Imprint 13 (16): 1-27.

Vihvelin, K. 2013. Causes, Laws, \& Free Will: Why Determinism Doesn't Matter. New York: Oxford University Press.

Watson, G. Agency and Answerability. New York: Oxford University Press.

Waller, B. Against Moral Responsibility. Cambridge, MA: MIT Press.

Whittle. A. "Dispositional Abilities". Philosopher's Imprint. Vol. 10, no. 12: 1-23

Wolf, S. 1990. Freedom within Reason. Oxford: Oxford University Press. 